\title{
Hepatoprotective Nature of Seaweed Alcoholic Extract on Acetaminophen Induced Hepatic Oxidative Stress
}

\author{
Hanumantha Rao Balaji Raghavendran, Arumugam Sathivel, and Thiruvengadam Devaki*
}

Department of Biochemistry and Molecular Biology, University of Madras, Guindy Campus, Chennai 600 025, India

(Received August 15, 2003; Accepted November 5, 2003)

\begin{abstract}
We have examined the protective effect of Sargassum polycystum (Phaeophyceae) alcoholic extract against a single dose of acetaminophen (intraperitoneally, $800 \mathrm{mg} / \mathrm{kg}$ body wt in saline solution) induced hepatic oxidative stress in experimental rats. The levels of serum glutamate oxaloacetate transaminase, pyruvate transaminase, lactate dehydrogenase, alkaline phosphatase, bilirubin, creatinine and blood urea were determined. The activities of glutathione, vitamins ( $\mathrm{C} \& \mathrm{E}$ ) and the levels of lipid peroxides in the liver homogenate were also determined. The acetaminophen induction resulted a significant elevation in the levels of serum marker enzymes, bilirubin, and creatinine with decreased blood urea. The activities of hepatic glutathione and vitamins (C \& E) were also significantly depleted with increased lipid peroxides in acetaminophen intoxicated rats. The oral pre-treatment with alcoholic extract of Sargassum polycystum (200 mg/kg body wt/day for a period of 15 days) showed hepatoprotective nature against acetaminophen induced biochemical changes in the serum and liver tissue. The animals pre-treated with Sargassum polycystum extract alone, did not show any toxicity in the liver tissue, which was confirmed by histopathological studies. These results suggest that the Sargassum polycystum alcoholic extract may probably acted as a natural antioxidant against acetaminophen induced hepatic oxidative stress.
\end{abstract}

Key words — Sargassum polycystum, acetaminophen, oxidative stress, lipid peroxides, antioxidant

\section{INTRODUCTION}

As a consequence of an increasing demand for the biodiversity in screening programs, seeking therapeutic drugs from natural products there is now a greater interest in the marine organism especially marine algae. ${ }^{1,2}$ The nutritional value of marine algae has long been recognized in the orient than in western world with limited use as a dietary part. ${ }^{3,4)}$ Seaweeds are low in fats but contain vitamins and bioactive compounds like terpenoids and sulphated polysaccharides a potential natural antioxidant, which are not found in land plants. ${ }^{5)}$ Reports show that the Sargassum sp. are found to have the highest free radical scavenging property. ${ }^{6,7)}$

Large doses of acetaminophen will cause acute dose dependent centrilobular hepatic necrosis in rats, mice, and man. ${ }^{8,9)}$ Acetaminophen toxicity in hepatocyte initiates a sequence of events that eventually leads to cell death. Antioxidants can inhibit these events suggesting that deleterious oxidative changes are involved. Toxic dose of acetaminophen will deplete the levels of hepatic reduced glutathione (GSH) followed by covalent binding of the reactive metabolite $\mathrm{N}$-acetly- $p$-benzoquinoneimine (NAPQI) formed during the biotransformation reaction by microsomal cytochrome $\mathrm{P} 450$ mixed function oxidase to tissue proteins. When GSH levels are low the reactive metabolite fails to be detoxified by conjugation, which ultimately leads to the accumulation of NAPQI, play a major role in hepatic oxidative stress. The involvement of reactive oxygen species (ROS) in acetaminophen hepatotoxicity has also been reported. ${ }^{10-12)}$

As sporadic status exist with regard to hepatoprotective nature of brown algae in animal model, we have attempted this study to assess the hepatoprotective nature of Sargassum polycystum alcoholic extract against acetaminophen induced hepatic oxidative stress in rats.

*To whom correspondence should be addressed: Department of Biochemistry and Molecular Biology, University of Madras, Guindy Campus, Chennai 600 025, India. Tel.: +91-2442351269; Fax: +91-244235-2494; E-mail: devakit@yahoo.co.uk 
Table 1. Hepatoprotective Effect of Sargassum polycystum Alcoholic Extract on Biochemical Responses of Experimental Animals to Acetaminophen (Means \pm S.D. for Six Animals in Each Group)

\begin{tabular}{|c|c|c|c|c|}
\hline Parameters & $\begin{array}{l}\text { Group I } \\
\text { Normal }\end{array}$ & $\begin{array}{l}\text { Group II } \\
\text { Acetaminophen } \\
\text { intoxicated }\end{array}$ & $\begin{array}{l}\text { Group III } \\
\text { Sargassum } \\
\text { Polycystum } \\
\text { Pre-treated }\end{array}$ & $\begin{array}{l}\text { Group IV } \\
\text { Sargassum } \\
\text { Polycystum } \\
\text { control }\end{array}$ \\
\hline SGOT (U/I) & $144.01 \pm 4.81$ & $187.71 \pm 5.70^{* * *}$ & $135.82 \pm 4.36^{*}$ & $145.63 \pm 4.79^{a)}$ \\
\hline SGPT (U/I) & $46.46 \pm 1.50$ & $101.00 \pm 3.90 * * *$ & $44.00 \pm 1.40 *$ & $\left.47.16 \pm 1.54^{a}\right)$ \\
\hline LDH ( $\mu$ mol pyruvate librated/hr/mg protein) & $95.30 \pm 8.30$ & $139.00 \pm 13.10^{* * *}$ & $78.69 \pm 8.90 * *$ & $96.00 \pm 8.31^{a)}$ \\
\hline ALP (mg/g phenol liberated/hr/mg protein) & $3.10 \pm 0.81$ & $7.10 \pm 0.89 * * *$ & $1.95 \pm 0.32 * *$ & $3.19 \pm 0.80^{a)}$ \\
\hline Bilirubin (mg/dl) & $0.45 \pm 0.03$ & $1.32 \pm 0.12 * * *$ & $0.43 \pm 0.24^{a)}$ & $0.44 \pm 0.03^{a)}$ \\
\hline Creatinine (mg/dl) & $0.96 \pm 0.08$ & $1.75 \pm 0.13 * * *$ & $\left.1.00 \pm 0.10^{a}\right)$ & $0.98 \pm 0.08^{a)}$ \\
\hline Blood urea (mg/dl) & $23.24 \pm 1.49$ & $16.17 \pm 1.04 * * *$ & $21.33 \pm 1.01 *$ & $\left.22.14 \pm 1.14^{a}\right)$ \\
\hline LPO (nmol malondialdehyde formed/mg protein) & $1.93 \pm 0.09$ & $2.92 \pm 0.18^{* * *}$ & $2.00 \pm 0.13^{a)}$ & $1.96 \pm 0.10^{a)}$ \\
\hline GSH (nmol/g wet tissue) & $5.42 \pm 0.12$ & $3.26 \pm 0.24 * * *$ & $5.41 \pm 0.09^{a)}$ & $5.50 \pm 0.20^{a)}$ \\
\hline Vitamin C (nmol/g wet tissue) & $2.65 \pm 0.18$ & $1.12 \pm 0.08 * * *$ & $2.31 \pm 0.08 * *$ & $2.52 \pm 0.21^{a)}$ \\
\hline Vitamin E (nmol/g wet tissue) & $2.87 \pm 0.23$ & $1.96 \pm 0.17 * * *$ & $2.67 \pm 0.22^{a)}$ & $2.85 \pm 0.25^{a)}$ \\
\hline
\end{tabular}

Comparisons made between: group I \& group II, group III \& I and group IV \& group I. $p$-Values: $*<0.05 ; * *<0.01 ; * * * 0.001$, a) Non Significant.

\section{MATERIALS AND METHODS}

Animals — Male Wistar strain albino rats, weighing about $120-150 \mathrm{~g}$ were obtained from the Fredrick institute for plant protection and toxicology, Padappai, Chennai, India. The animals were fed with a commercial pelleted diet (M/s Hindustan Foods Ltd, Bangalore, India) and water ad libitum.

Seaweed Collection — The seaweed Sargassum polycystum was collected from Mandapam, Gulf of Mannar region, Rameswaram India. The species identification was done by Prof. V. Krishnamurthy (Krishnamurthy institute of algology, Chennai, India). The seaweed sample was washed in seawater and fresh water thoroughly to remove the epiphytes and other contamination. Then the sample was air dried in shade and coarsely powdered. The powdered material was then extracted with alcohol in cold for a period of one week with occasional shaking. The crude syrup extract obtained was then concentrated and lyophilized to a brownish residue at $45^{\circ} \mathrm{C}$ under reduced pressure using rotary evaporator (Yield: $12-15 \%$ ). The phytochemical analysis was carried out with raw seaweed powder and alcoholic extract. ${ }^{13)}$

Experimental Protocol — The experimental animals were divided into four groups, each group comprising six animals.

Group I: Normal control rats.

Group II: Acetaminophen $(800 \mathrm{mg} / \mathrm{kg}$ body wt intraperitoneally) in saline solution in a boiling waterbath and used after cooling at $37^{\circ} \mathrm{C}$.

Group III: Orally Pre-treated with seaweed extract $(200 \mathrm{mg} / \mathrm{kg}$ body wt daily for a period of 15 days) prior to acetaminophen induction $(800 \mathrm{mg} /$ $\mathrm{kg}$ body wt intraperitoneally).

Group IV: Orally Pre-treated with seaweed extract alone $(200 \mathrm{mg} / \mathrm{kg}$ body wt daily for a period of 15 days).

At the end of the experimental period the animals were fasted overnight and then sacrificed by cervical decapitation. Blood was collected without any anti-coagulant for serum separation. Liver was excised immediately and washed in ice-cold saline. A portion was homogenized in $0.1 \mathrm{M}$ Tris- $\mathrm{HCl}$ buffer. $\mathrm{pH} 7.4$ at $4^{\circ} \mathrm{C}$ in a potter-Elvejhem homogenizer using Teflon pestle at $600 \mathrm{rpm}$ for $3 \mathrm{~min}$. The levels of serum glutamate oxaloacetate transaminase. ${ }^{14)}$ pyruvate transaminase, lactate dehydrogenase. ${ }^{15)}$ alkaline phosphatase. ${ }^{16)}$ bilirubin. ${ }^{17)}$ creatinine ${ }^{18)}$ and blood urea ${ }^{19)}$ were determined. Liver homogenate was used for assaying the activities of glutathione. ${ }^{20)}$ vitamins (C \& E) and lipid peroxides. ${ }^{21-23)}$

Student's t-test was used to assess statistical difference. Results are expressed as mean \pm S.D.

\section{RESULTS}

As shown in the Table 1, group II rats treated with single dose of acetaminophen developed severe hepatic damage as compared to the group I con- 


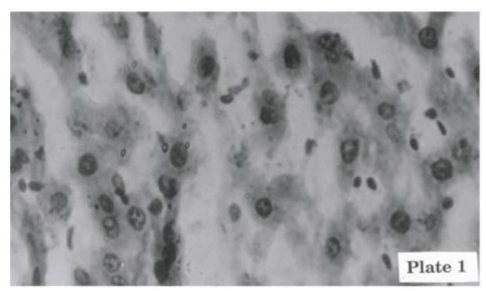

Fig. 1a. Illustrates a Section of Rat Liver Showing Normal Architechture

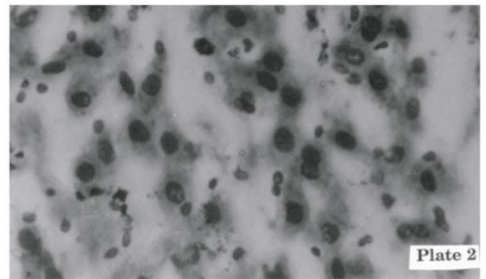

Fig. 1b. Illustrates a Section of Rat Liver Pre-Treated with Sargassum polysystum Showing Normal Architechture

trols. This was evidenced by a marked elevation in the levels of hepatic markers, bilirubin, creatinine, with lowered blood urea levels. The activities of glutathione and vitamins ( $\mathrm{C} \& \mathrm{E}$ ) were also depleted with increased levels of lipid peroxides in liver tissue. The pre-treated group III rats showed a significant improvement in the levels of all severely altered biochemical parameters when compared with acetaminophen intoxicated group II experimental animals. The histopathological studies (Fig. 1) of rat liver tissue shows the normal control, Sargassum polycystum control, acetaminophen intoxicated and Sargassum polycystum pretreated prior to acetaminophen intoxication.

\section{DISCUSSION}

The animals treated with acetaminophen resulted a significant hepatic damage as elicited by the elevated levels of hepatospecific serum markers [serum glutamate oxaloacetate transaminase (SGOT), serum glutamate pyruvate transaminase (SGPT), lactate dehydrogenase (LDH), and alkaline phosphatase (ALP)]. These changes in the marker levels will reflect in hepatic structural integrity. The markers are cytoplasmic in origin and released into the circulation after cellular damage. ${ }^{24,25)}$ The rise in the SGOT is usually accompanied by an elevation in the levels of SGPT, which play a vital role in the conversion of amino acids to keto acids. ${ }^{26)}$ The pre-

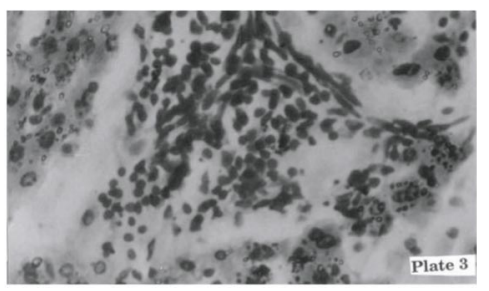

Fig. 1c. Illustrates a Section of Rat Liver Treated with Acetaminophene Showing Inflammatory Infiltration

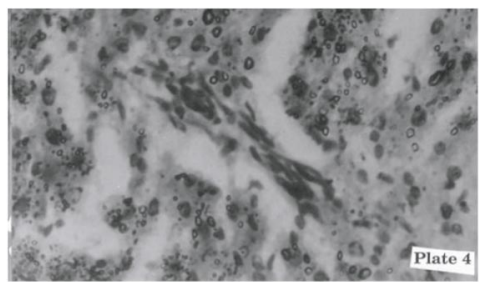

Fig. 1d. Illustrates a Section of Rat Liver Pre-Treated with Sargassum polysystum Prior to Acetaminophen Induction Showing a Pattern of Reduced Inflamatory Infiltration

treatment with alcoholic extract of Sargassum polycystum attenuated the elevated levels of serum markers. The normalization of serum markers by seaweed extract suggests that they are being able to condition the hepatocytes so as to protect the membrane integrity against acetaminophen induced leakage of marker enzymes into the circulation.

The elevation in the levels of creatinine and bilirubin has been reported in acetaminophen induced hepatotoxicity. ${ }^{27,28)}$ Bilirubin, an endogenous organic anion binds reversibly to albumin and it is transported to the liver, and then conjugated with glucuronic acid and excreted in the bile. Hepatobiliary disease is indicated when conjugated fraction of total bilirubin exceeds the upper limit of normal, even if the total serum bilirubin is normal or near normal. ${ }^{29)}$ The normalization of blood urea, bilirubin and creatinine in seaweed extract pre-treated rats further indicates the protective nature of seaweed extract on hepatic cells when compared with acetaminophen intoxicated rats.

Acetaminophen on over dose will elevate the malondialdehyde (MDA) a product of lipid peroxidation. Therefore an increase in the liver MDA levels indicates an increase in the degree of lipid peroxidation, a well known mechanism of liver damage. ${ }^{30)}$ In addition, the extensive lipid peroxidation results in membrane disorganization by peroxidizing the highly unsaturated fatty acids, which in turn alters the ratio of polyunsaturated to other fatty acids 
leading to a decrease in the membrane fluidity, which may be sufficient to cause cell death. ${ }^{31)}$ A significant decrease in the levels of lipid peroxides in seaweed pre-treated rats suggests that the extract may have the ability to protect the liver from free radical injury induced by acetaminophen.

The hepatotoxic doses of acetaminophen will deplete the normal levels of hepatic glutathione, when NAPQI covalently binds to cysteine groups on proteins as 3-(cystein-S-yl)acetaminophen adducts. ${ }^{32)}$ The glutathione protects hepatocytes by combining with the reactive metabolite of paracetamol thus preventing their covalent binding to liver proteins. ${ }^{33)}$ The seaweed extract pre-treated rats may limit the depletion of GSH and the severity of the oxidative stress by preventing the protein adduct formation, thereby protecting liver proteins.

The levels of vitamins (C \& E) were significantly depleted in acetaminophen intoxicated rats. This depletion may be due to the excessive utilization of non-enzymic antioxidants ( $C$ \& E) involved in quenching the enormous free radicals produced during acetaminophen intoxication. ${ }^{34)}$ The seaweed pretreated rats showed an improvement in the levels of vitamins. The levels of GSH also found to have some positive relation with vitamins (C \& E) i.e. GSH may maintain the vitamin $\mathrm{E}$ levels either by direct reduction of $\alpha$-tocopheroxyl radical to vitamin $\mathrm{E}$ or via the reductive action of vitamin $\mathrm{C}$. Thus an improvement in the levels of vitamin $\mathrm{E}$ against oxidative stress induced by acetaminophen may therefore be a secondary event to the improved hepatic glutathione and ascorbate redox state. ${ }^{35)}$

The present study thus shows that the hepatoprotective nature of Sargassum polycystum alcoholic extract against acetaminophen induced hepatic oxidative stress may be due to the presence of sulphated compounds, which are found to have free radical scavenging property. ${ }^{36}$

Acknowledgements The authors are grateful to Prof. V. Krishnamurthy (Krishnamurthy Institute of Algology, Chennai, India) for his timely help in species identification and guidance throughout this work. Dr. N. Kaliaperumal (CMFRI, Rameswaram India) for his help during the period of seaweed collection. Authors also thank Dr. C. N. Srinivas MD Pathology [EMS diagnostic and research center. Chennai, India] for his help in carrying out histopathological studies.

\section{REFERENCES}

1) Faulkner, D. J. (1993) Marine natural products chemistry: introduction. Chem. Rev., 93, 1671-1673.

2) Scheuer, P. J. (1987) Bioorganic marine chemistry, vols. 1-3 Springer. Berlin Heidelberg, New York.

3) Indegaard, M. and Ostgaard, K. (1991) Polysaccharide for food and Pharmaceutical uses in: seaweed resources in Europe: uses and potential (Guiry, M. D. and Blunden, G., Eds.), John Wiley and Sons Ltd. England, pp. 169-183.

4) Smidsrod, R. and Christensen, B. E. (1991) Molecular structure and physical behavior of seaweed colloids as compared with microbial polysaccharide in seaweeds resources in Europe uses and potential (Guiry, M. D. and Blunden, G., Eds.), John Wiley and sons' Ltd. England. pp. 185-215.

5) Lahaye, M. and Kaffer, B. (1997) Seaweed dietary fibers structure physicochemical and biological properties relevant to intestinal physiology. Sci. Aliments., 17, 563-564.

6) Matsukawa, R. (1997) A comparison of screening methods for antioxidant activity in seaweeds. J. Appl. Phycol., 9, 29-35.

7) Yan, X., Nagata, T. and Fan, X. (1998) Antioxidant activities in some common seaweeds. Plant. Foods. Hum. Nutr., 52, 253-262.

8) Mitchell, J. R., Jollow, D. J., Potter, W. Z., Davis, D. C., Gillette, J. R. and Brodie, B. B. (1973a) Acetaminophen induced hepatic necrosis I role of drug metabolism. J. Pharmacol. Exp. Ther., 187, 185.

9) Boyd, E. H. and Bereczky, G. M. (1966) Liver necrosis from paracetamol. Br. J. Pharmacol., 26, 606.

10) Dahlin, D. C., Miwa, G. T., Lu, A.Y. H. and Nelson, S. D. (1984) N-acetyl-p- benzoquinone imine a cytochrome P-450 mediated oxidation product of acetaminophen. Proc. Natl. Acad. Sci. U.S.A., 81, 1327-1331.

11) Fairhurst, S., Bgber, D. J., Clark, B. and Horton, A. A. (1982) Studies on Paracetamol - induced lipid peroxidation. Toxicology, 23, 249-259.

12) Savides, M. C. and Woehme, F. (1983) Acetaminophen and its toxicity. J. Appl. Toxicol., 3, 96-111.

13) Anggadiredja, J., Hasanudin Sidiq, A. S., Pratomo, S. and Rudyansyah, A. (1996) Screening of marine algae from Warambadi seashore Sumba island of Indonesia for antibacterial activity. Phytomedicine, $\mathbf{3}$ (Suppl I), 37.

14) Retimen, S. and Frankel, S. A. (1957) Colorimetric method for determination of serum glutamic oxaloacetic and glutamic pyruvate transaminases. Am.J. Clin. Pathol., 28, 56-63.

15) King, J. (1965) The dehydrogenase of oxidoreductase-lactate dehydrogenase. In Practical clinical enzymology (King, J. C., Ed.), Van D No strand Com- 
pany, London, pp. 83-93.

16) Kind, P. R. N. and King, E. J. (1954) Estimation of plasma phosphatases by determination of hydrolyzed phenol with antipyrene. J. Clin. Pathol., 7, 322-330.

17) Malloy, H. T. and Evelyn, K. A. (1937) The determination of bilirubin with the photometric colorimeter. J. Biol. Chem., 119, 481-490.

18) Broad, J. and Sirota, J. H. (1948) Renal clearance of endogenous creatinine in man. J. Clin. Innvest., 27, 645.

19) Natelson, S., Scott, M. L. and Beffa, C. A. (1951) Rapid method for the estimation of urea in biological fluids, by means of the reaction between biacetyl and urea. Am. J. Clin. Pathol., 21, 275-281.

20) Moron, M. S., Depierre, J. W. and Mannervik, B. (1979) Levels of glutathione, glutathione reductase and glutathione-s-transferase activities in rat lung and Liver. Biochim. Biophys. Acta, 5820, 62-68.

21) Omaye, S. T., Tornbull, T. O. and Sauberlich, H. E. (1979) Selected methods for the determination of ascorbic acid in cells, tissue and fluids. Methods Enzymol., 62, 1.

22) Desai, D. J. (1984) Methods in enzymology, (Parker, Ed.) Academic press, New York, Vol. 105, p. 138.

23) Ohkawa, H., Ohishi, N. and Yagi, K. (1979) Assay of lipidperoxides in animal tissues by thiobarbituric acid reaction. Anal. Biochem., 95, 351-358.

24) Mohan Rao, G. M., Morghmom, L. O., Kabur, M. N., Benmohamud, B. M. and Ashibanic, K. C. (1989) Serum glumatic oxaloacetic transaminase (GOT) and glutamic pyruvic transaminase (GPT) levels in diabetes mellitus. In. J. Med. Sci., 5, 188-192.

25) Lin, S. C., Chung, T. C., Ueng, T. H., Linn, Y. H., Hsu, S. H., Chiang, C. L. and Lin, C. C. (2000) The hepatoprotective effects of Solanum alatam moench on acetaminophen - induced hepatotoxcity in mice. Am. J. Clin Med., 28, 105-114.

26) Sallie, R., Tredger, J. M. and Willaiam (1999) Drugs and the liver. Biopharm. Drug Dispos., 12, 251-259.

27) Ellenhorn, M. J. (1997) Ellenhorn's medical toxicology and treatment of human poisoning (Philadelphia, $2^{\text {nd }}$ Eds.), Williams and Wilkins Company, pp. 180-195.
28) Yamaguchi, T., Terakado, M., Hario, F., Aoki, K., Tanaka, M. and Nakajima, H. (1996) Role of bilirubin as antioxidant in an ischemia -reperfusion of rat liver and induction of heme oxygenase. Biochem. Biophys. Res. Commun., 223, 129-135.

29) Rosen, H. R. and Keefe, E. B. (1998) Laboratory evaluation of the patient with signs and symptoms of liver disease. In clinical practice of gasteroenterology (Brandt, L. J., Ed.), Churchil Living stone, Philadelphia, pp. 812-820.

30) Trible, D. L., Aw, T. Y. and Jones, D. P. (1987) The pathophysiological significance of lipid peroxidation in oxidative cell injury. Hepatology, 7, 377-387.

31) Rotruck, J. T., Pope, A. L., Ganther, H., Awanson, A. B., Haffeman, D. G. and Hofckstra, W. G. (1979) Selenium: Biochemical role as a component of glutathione peroxides. Science, 179, 588-590.

32) Tirmenstein, M. A. and Nelson, S. P. (1989) Sub cellular binding and effects on calcium homeostasis produced by acetaminophen and a non-hepatotoxic regioisomer 3-hydroxyacetanilide in mouse liver. $J$. Biol. Chem., 264, 9814-9819.

33) Vermeulen, N. P. E., Bessems, J. G. M., Van, D. E. and Straat, R. (1992) Molecular aspects of paracetamol induced hepatotoxicity and its mechanism based prevention. Drug Metab. Rev., 24, 367407.

34) Ip, S. P. and Ko, K. M. (1996) The crucial antioxidant action of schisandrin $\mathrm{B}$ in protecting against ccl4 hepatotoxicity in mice a comparative study with butylated hydroxytoulene. Biochem. Pharmacol., 52, 1687-1693.

35) Jayachandran, M., Lalithapriya, S. and Pannerselvam, C. (1995) Effect of ascorbic acid supplementation of tissue ascorbic acid status and nucleic acid content of young and aged rats. J. Clin. Biochem. Nut., 19, 131-36.

36) Xue, C., Fang, Y., Lin, H., Chen, L., Li, Z., Deng, D. and Lu, C. (1998) Chemical characters and antioxidant properties evaluated in a phosphotidylcholine liposomal suspension and organic solvents. Biosci. Biotechnol. Biochem., 62, 206-209. 